\title{
Comercialização ilegal de carne de animais silvestres em feiras livres de algumas cidades do Estado do Amazonas (Brasil)
}

Illegal marketing of wild animal meat at open markets in some cities in the State of Amazonas (Brazil)

Comercialización ilegal de carne de animales salvajes en mercados abiertos en algunas ciudades del estado de Amazonas (Brasil)

Mendes FLS. Comercialização ilegal de carne de animais silvestres em feiras livres de algumas cidades do Estado do Amazonas (Brasil). Rev Colombiana Cienc Anim. Recia. 2020; 12(2):e765. https://doi.org/10.24188/recia.v12.n2.2020.765

Universidad de Sucre, Colombia

Los autores permiten a RECIA reimprimir el material publicado en él. En caso de que un autor quiera traducir o usar una publicación parcial o completa de nuestro Diario, el autor debe obtener un permiso por escrito del editor de la revista.

Copyright (C) 2020. El (los) autor (es), Revista Colombiana de Ciencia Animal - RECIA. 2020. Este es un artículo de acceso abierto distribuido bajo los términos de Creative Commons Attribution 4.0 (https://creativecommons.org/licenses/by-nc-sa/4.0/), El uso, distribución o reproducción está permitido, siempre que se acrediten al autor original y al propietario del copyright y que se cite la publicación original en esta revista, de acuerdo con la práctica académica aceptada. No se permite el uso, distribución o reproducción que no cumpla con estos términos. 


\title{
Comercialização ilegal de carne de animais silvestres em feiras livres de algumas cidades do Estado do Amazonas (Brasil)
}

\author{
Illegal marketing of wild animal meat at open markets in some cities in the State of \\ Amazonas (Brazil)
}
Comercialización ilegal de carne de animales salvajes en mercados abiertos en algunas ciudades del estado de Amazonas (Brasil)

Fabrício Lemos de Siqueira Mendes

Universidade Federal do Pará, Brasil.

fabriciolsm@ufpa.br

(D) https://orcid.org/

DOI: https://doi.org/10.24188/recia.v12.n2.2020.765

Recepción: 15 marzo 2020

Aprobación: 27 junio 2019

Publicación: 10 julio 2020

\begin{abstract}
RESUMO
Animais Silvestres (AS) estão sempre presentes em discussões globais durante as últimas décadas nas questões de conservação. 0 Brasil apresentando maior biodiversidade do planeta, faz com que haja um forte interesse nessa riqueza, não só nacionalmente, mas também internacional. 0 objetivo deste artigo é quantificar a comercialização ilegal de AS, para o consumo da dieta alimentar em algumas cidades da Amazônia. A metodologia utilizada foi pesquisa bibliográfica, a aplicação de questionários e entrevistas aos frequentadores das feiras livres de oito cidades do estado do Amazonas. Os resultados comprovaram que os frequentadores entrevistados das feiras livre compram ilegalmente animais silvestres, para fonte de proteína alimentar de suas dietas. Os animais mais comumente apreciáveis na dieta alimentar são os mamíferos. Com o estudo concluiu-se que nessas cidades o comércio ilegal de animais silvestres está associado principalmente as questões culturais e falta de opções econômicas na região. Deste modo, para amenizar esse problema é necessário a implementação de Políticas Públicas Ambientais, Educação Ambiental, maior rigor nas fiscalizações e incentivo a criação de AS em cativeiro.
\end{abstract}

Palavra-chave: Amazônia; Animal; Captura; Hábito Cultural; Selvagens.

\begin{abstract}
Wild Animals (WA) are always present in global discussions during the last decades on conservation issues. Brazil presenting the greatest biodiversity on the planet, makes it a strong interest in this wealth, not only nationally, but also internationally. The purpose of this article is to quantify the illegal commercialization of AS, for the consumption of the diet in some cities in the Amazon. The methodology used was bibliographic research, the application of questionnaires and interviews to the regulars of open markets in eight cities in the state of Amazonas. The results showed that the interviewees of the open markets bought illegally wild animals, as a source of dietary protein in their diets. The most commonly appreciable animals in the diet are mammals. The study concluded that the illegal trade in wild animals in these cities is mainly associated with cultural issues and lack of economic options in the region. Thus, to alleviate this problem, it is necessary to implement Environmental Public Policies, Environmental Education, stricter inspections and encourage the creation of SA in captivity.
\end{abstract}

Keyword: Amazon; Animal; Capture; Cultural Habit; Wild.

Mendes FLS. Comercialização ilegal de carne de animais silvestres em feiras livres de algumas cidades do Estado do Amazonas (Brasil). Rev Colombiana Cienc Anim. Recia. 2020; 12(2):e765. https://doi.org/10.24188/recia.v12.n2.2020.765 


\section{RESUMEN}

Los animales salvajes (AS) siempre están presentes en las discusiones mundiales durante las últimas décadas sobre temas de conservación. Brasil, que presenta la mayor biodiversidad del planeta, lo convierte en un gran interés en esta riqueza, no solo a nivel nacional, sino también internacional. El propósito de este artículo es cuantificar la comercialización ilegal de AS, para el consumo de la dieta en algunas ciudades del Amazonas. La metodología utilizada fue la investigación bibliográfica, la aplicación de cuestionarios y entrevistas a los clientes habituales de los mercados abiertos en ocho ciudades del estado de Amazonas. Los resultados mostraron que los entrevistados de los mercados abiertos compraron animales salvajes ilegalmente, como una fuente de proteína en la dieta en sus dietas. Los animales más apreciables en la dieta son los mamíferos. El estudio concluyó que el comercio ilegal de animales salvajes en estas ciudades se asocia principalmente con problemas culturales y la falta de opciones económicas en la región. Por lo tanto, para aliviar este problema, es necesario implementar Políticas Públicas Ambientales, Educación Ambiental, inspecciones más estrictas y alentar la creación de SA en cautiverio.

Palabra clave: Amazonas; Animal; Captura; Hábito Cultural; Salvaje.

\section{INTRODUÇÃo}

A estimativa da biodiversidade do Brasil abrange cerca de 10\% de todas as espécies existentes no globo (1). Calcula-se que a fauna ocupante neste país apresenta cerca de $60 \%$ de anfíbios, 35\% de primatas e répteis, e $10 \%$ de aves, do globo terrestre $(2,3)$. Sabe-se, hoje, que a biodiversidade é uma das características mais marcantes da Amazônia, visto que tal região abriga cerca de 60 mil espécies de plantas superiores, 2,5 milhões de espécies artrópodes, 2.000 espécies de peixes e 300 espécies de mamíferos (4).

Diante desses números, ressalta-se que o Brasil é o maior detentor da diversidade biológica do planeta (5). Essa informação tem por base o Relatório da Conservation Internacional, o qual afirma que o Brasil é o país mais rico quanto à megadiversidade, detendo aproximadamente 15\% do número de espécies do planeta (6). Porém, essa biodiversidade pode estar sob ameaça, uma vez que diversas modificações antrópicas são imputadas ao habitat amazônico, principalmente o comércio ilegal. Tal fator é considerado um dos maiores responsáveis pela redução e extinção das populações de Animais Silvestres (AS). E, em determinadas regiões do país, como a Amazônia, é uma das principais alternativas de subsistência em áreas rurais e ribeirinhas (7).

A caça indiscriminada é outro fator relevante que pode causar impacto nas espécies (8). Isso pode ocasionar: diminuição da densidade populacional das espécies caçadas; redução da massa corpórea média das populações, em consequência da seleção dos animais maiores; diminuição da idade média da primeira gestação; aumento da fecundidade média das fêmeas; redução do número de animais das classes etárias maiores; diminuição da produtividade futura das populações caçadas; extinção local das espécies vulneráveis; alteração na estrutura das comunidades biológicas por meio da diminuição da representação de espécies maiores; mudança na composição das comunidades biológicas; diminuição significativa na produção das comunidades biológicas; e algumas espécies estão mudando seu período de atividade de diurno para noturnos (9). Deste modo, todos esses fatores, somado a caça indiscriminada são fortes indícios que podem levar as espécies em extinção.

Quando se trata da Amazônia, há uma enorme preocupação com a questão abordada, visto que a redução das populações de AS ocorre devido ao consumo de carne pelas populações do interior amazônico. Na parte oriental dessa região, há um processo de colonização intenso, o qual acelera a diminuição da população de mamíferos. Mas, quando se trata de biomas brasileiros, não só a fauna amazônica, mas a do Pantanal, a do Cerrado e da Caatinga, por apresentarem espécies raras, atraem a cobiça de colecionadores, caçadores, coureiros, contrabandistas e receptores (10).

A Floresta Amazônica é a maior floresta tropical do planeta e apresenta ecossistemas variados. Além da floresta úmida de terra firme, que é a mais conhecida, apresenta diferentes tipos de matas, campos abertos e algumas espécies de cerrado. Esta floresta é de fundamental importância para o equilíbrio do planeta, já que seus rios representam cerca de $20 \%$ das reservas de água doce global. Além disso, a Amazônia também abrange grandes reservas minerais (11).

Essa região abriga uma grande variedade de espécies da flora e fauna. No que diz respeito aos animais, o maior número é de insetos, mas a floresta abriga também grande variedade de mamíferos e aves. Em seu trecho alagado, são comuns os mamíferos aquáticos como o peixe-boi (Trichechus inunguis Linnaeus, 1758), lontra (Pteronura brasiliensis Gmelin, 1788) 
e os botos (Inia geoffrensis de Blainville, 1817), assim como jacarés (Caiman crocodilos), tartarugas (Podocnemis expansa) e cobras (serpentes) (11).

Em decorrência da enorme fauna na Amazônia, vários são os animais cobiçados pelo comércio ilegal. Mas, vale ressaltar que o grupo das aves são as mais requisitadas pelos seus cantos e beleza e, além disso, sua ampla distribuição geográfica e sua diversidade tornam o grupo mais visado para mantê-las em cativeiro (12). No Brasil, cerca de $80 \%$ dos animais capturados pertencem ao grupo das aves, em decorrência da rica diversidade presente na América do Sul (8).

Quando se trata da captura de AS para inclusão na dieta alimentar, dois estados brasileiros chamam atenção: Amapá e Amazonas. Neles, os répteis foram os animais mais apreendidos pelos órgãos de fiscalização (13). Porém, na Amazônia como um todo são os mamíferos que são mais consumidos pela população presente no interior da região (14).

No que se refere às modalidades que envolvem a comercialização ilegal de AS no Brasil, são quatro: a primeira é o tráfico para subsistência realizado nas beiras das estradas pela população local, para próprio sustento. Em segundo, as feiras-livres e suas proximidades, onde há o tráfico de encomenda. Na terceira, existem os que abastecem o acervo de colecionadores que atuam na clandestinidade, considerado o tráfico de animais raros. E, por último, não menos importante, tem-se o tráfico de ovos, modalidade que vem se aperfeiçoando e se tornado mais comum (13). No âmbito internacional, 30\% do comércio ilegal de AS é destinado à outros países, localizados, principalmente, na Europa, Ásia e na América do Norte $(15,16)$.

Diante da enorme proporcionalidade das apreensões, tem-se consequentemente, uma grande perda da fauna da região norte brasileira, o que empobrece a biodiversidade. Neste sentido o objetivo deste artigo é caracterizar a preferência, dos frequentadores de feiras-livres de algumas cidades do estado do Amazonas, em termos de consumo e posse de espécies silvestres de animais comercializadas.

\section{MATERIAL E MÉTODOS}

Caracterização da Área Estudada. Com uma área de $3.869 .637,9$ km², correspondente a 45,27\% do território brasileiro, a região Norte é constituída pelos estados do Acre, Amapá, Amazonas, Pará, Rondônia, Roraima e Tocantins (11). Sua área está localizada entre o maciço das Guianas ao norte, o planalto Central ao sul, a cordilheira dos Andes a oeste, e o oceano Atlântico a noroeste. De clima equatorial, é banhada pelos rios grandes da bacia amazônica.

A área de estudo (Figura 1) da pesquisa foi o estado do Amazonas, que fica no centro da região Norte e é cortado pela linha do Equador. É o maior estado brasileiro, ocupa mais de 18\% do território do país. Seu território está distribuído pelo planalto das Guianas, ao norte, e pelas encostas do planalto brasileiro, ao sul, (11). No Amazonas foram selecionadas

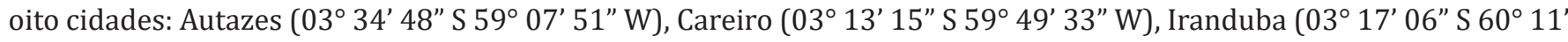

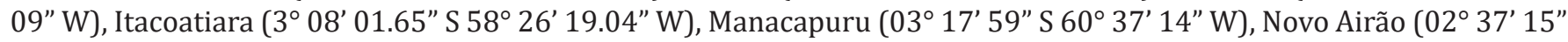

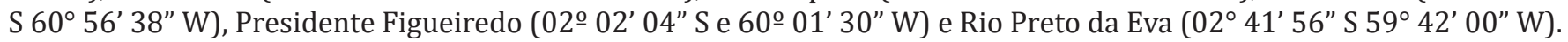

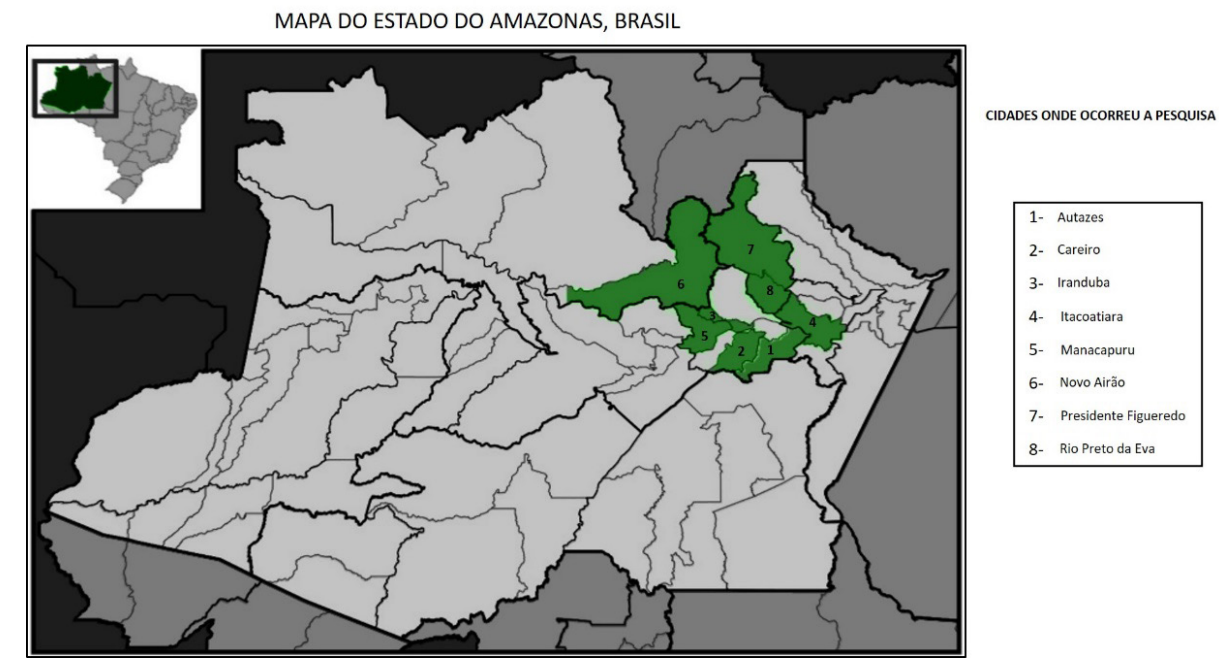

Figura 1. Mapa do Estado do Amazonas (Brasil) com as respectivas cidades onde foi desenvolvida a pesquisa. Fonte: Elaborado por Gomes, 2020. 
Coleta e Análise dos Dados. As cidades selecionadas se deram a partir do survey realizado, uma vez que o levantamento inicial para este tipo de pesquisa é fundamental. Então, identificou-se por meio dos Relatório de Alto de Infração do Instituto Brasileiro do Meio Ambiente e dos Recursos Renováveis Naturais (IBAMA), que as cidades selecionadas apresentavam fortes indícios, de venda e consumo ilegal de AS. Outro critério foi o do acesso "fácil" de transporte viário e fluvial para se chegar a essas cidades, uma vez que o escoamento de comercialização de AS é mais frequente via acesso rodo fluvial.

Nas visitas às feiras-livres dessas cidades, foi aplicado um questionário aos frequentadores, para verificar o consumo, o destino, o motivo da compra, a procedência e a posse de AS. No questionário, as perguntas foram "diluídas", para que o objetivo da pesquisa não fosse identificado, uma vez que poderiam negar a entrevista, com receio de alguma punição. De fato, tanto frequentadores, vendedores e presidentes de associações dos feirantes, não raras vezes, se negam a participar de pesquisas investigativas. E justificam alegando as ações de fiscalização realizadas pelas instituições federais que controlam essa questão, precisamente, o IBAMA e a Polícia Federal que são as mais atuantes na região.

As coletas de dados nas feiras-livres foram realizadas de julho e agosto de 2008. Cada local foi visitado uma única vez, para não haver possíveis sobreposições de entrevistas junto aos frequentadores, pois algumas feiras eram pequenas demais, possibilitando encontrar o mesmo entrevistado em dias e horários diferentes. Com isso, foi estabelecido que em cada feira-livre fossem aplicados 20 questionários, totalizando 160 entrevistados.

Os dados obtidos nos questionários, sofreram análise estatística tendo sido tabulados em termos de frequências absolutas por cidade e classe (peixes, répteis, aves e mamíferos). Só foi possível identificar na categoria taxonômica Classe, visto que os entrevistados desconhecem categorias menores, como gêneros e espécies. Em seguida os dados foram inseridos em gráficos para melhor entendimento.

Ainda com relação às feiras-livres, foi possível gravar algumas entrevistas com vendedores. Porém, vale ressaltar que pesquisa foi realizada no anonimato. A não identificação do propósito dela, foi devido durante o survey em 2007, os atores envolvidos não se propuseram a assinar o Termo de Consentimento de Livre Esclarecimento (TCLE) em função de que na Amazônia, o assunto estudado (compra AS para o consumo da dieta alimentar) é ilegal perante a Lei brasileira, e esses feirantes temiam em se comprometer com suas respostas.

\section{RESULTADOS}

Através dos 160 questionários e entrevistas realizadas nas feiras livres visitadas dessas cidades no estado do Amazonas, constatou-se um forte indício de caça e comércio ilegal. Exemplo disso foi observado na cidade de Manacapuru. Durante a entrevista com um dos comerciantes da feira-livre, após muita insistência, este permitiu o registro fotográfico de um espécime sendo vendido em seu estabelecimento (Figura 2). Ao ser indagado sobre sua procedência este informou que "[...] é a população ribeirinha (pessoas que residem às margens dos rios na região amazônica), em torno da cidade, que traz esses animais aqui, daí a gente vende para a população que vem aqui comprar. Tem feira na periferia da cidade, que tem vários animais sendo vendidos lá, inclusive macaco, mas não lhe aconselho fazer esse tipo de trabalho lá, é muito perigoso [...] as pessoas procuram esse tipo de carne porque a carne de caça é bem mais em conta em relação à carne de gado $[\ldots] "$.

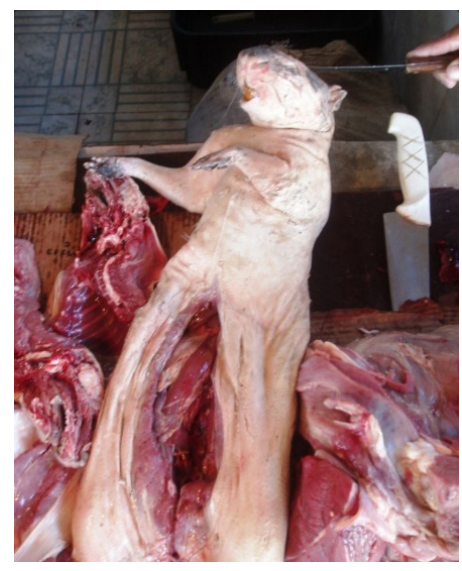

Figura 2: Exemplar de Cuniculus paca (paca) vendida na feira-livre de Manacapuru (AM). Fonte: Mendes, 2008. 
Na cidade de Rio Preto da Eva apesar de não haver comercialização na própria feira, constatou-se o comércio, por encomenda, como revela um dos frequentadores da feira-livre "[...] aqui na feira é muito difícil encontrar carne de AS exposta à venda, mas tem gente que vende por encomenda. Se o senhor quiser, o senhor encontra paca, tatu (Dasypodidae) e anta (Tapirus terrestres), apesar de ser arriscada a venda [...] eu gosto de caçar, e todas as vezes que posso eu vou. Ontem mesmo eu persegui uma anta, mas não consegui pegar ela. Eu caço por esporte e o que eu caço eu como, eu não vendo [...] já comi carne de anta, tatu, paca e capivara (Hydrochoerus hydrochaeris) [...]".

Além da encomenda, a tática de levar o comprador em locais onde se encontra a mercadoria também é muito utilizada na cidade. Alguns vendedores também adotam a estratégia de abordar os compradores na feira-livre, anotar o pedido e entregar, no máximo, em uma semana. Quando há disponibilidade de caça para pronta-entrega, é realizada no mesmo dia.

Em Careiro, as informações obtidas não se diferenciam muito das demais. Os frequentadores informaram que é difícil encontrar carne de AS na feira-livre desta cidade. Porém, se encontra de maneira "camuflada", tanto para o consumo alimentar como para estimação. Lá existe uma residência, fora dos domínios da cidade, em que um morador cria uma anta de estimação, informou o entrevistado. Além disso, complementa “[...] teve um dia que passou por aqui um rapaz com um filhote de peixe-boi vivo, não sei o que ele ia fazer com o bicho, mas tem gente que vem só de Manaus para comprar esse tipo de animal aqui em Careiro. Se você quiser comprar mesmo bicho proibido, basta ir a Manacapuru [...]".

Porém, nem todos que frequentam as feiras-livres visitadas possuem o hábito de comprar carne de AS, uma vez que caçá-los é mais prazeroso, conforme afirmação de um dos vendedores. Em Iranduba, isto foi registrado durante uma entrevista, quando o vendedor revelou que tem prazer de sair aos finais de semana com um amigo para caçar AS na floresta. Os artefatos para esse tipo de atividade, revela o vendedor, são armas de fogo e cães de caça, que servem para rastrear, localizar e pegar a presa. Além dessas informações, o mesmo vendedor comentou que "[...] tem gringo que, pelo menos uma vez por ano, vem aqui caçar e contratam a gente [...] eles pagam tudo: voadeira, diária, bebida, comida, cigarro e diesel, tudo em dólar. Eles passam aqui cerca de dez dias dentro da mata [...] são todos estudantes que já vem com pacote fechado por lá. Eu chego a ganhar numa dessas, mais de seis mil reais [...]".

Pelo exposto, percebeu-se que não somente a população tradicional da Amazônia tem o hábito de caçar, com também estrangeiros, sempre tiverem essa atividade como lazer. Em Itacoatiara, um caçador "aposentado" afirma que, na década de 1950 e 1960, tinha como a caça uma atividade, tanto de subsistência como de lazer. Porém, para caçar nos dias de hoje, afirma, deve-se ter muito cuidado com o IBAMA.

Nas cidades do estado do Amazonas é evidente, conforme a Figura 3, a frequência absoluta de mamíferos consumidos. A cidade de Itacoatiara foi a que mais apresentou frequentadores que compram carne de mamíferos (41 citações), seguido dos frequentadores da feira de Autazes (37 citações). As cidades de Iranduba e Manacapuru foram as únicas que apresentaram apenas duas classes (mamíferos e répteis) de AS consumidas, as demais, apresentaram as quatro classes. Além disso, dentre todos as cidades pesquisadas, Iranduba apresenta a menor frequência absoluta (19 citações) de carne de mamíferos consumida.

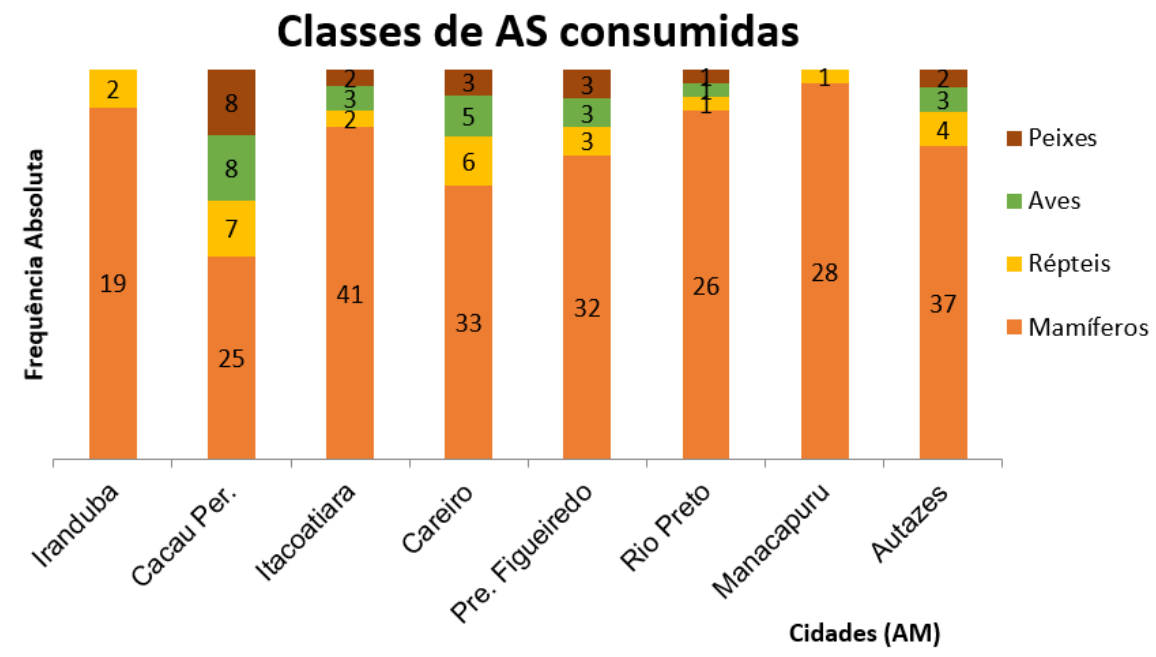

Figura 3: Frequência absoluta de classes de AS consumidas nas cidades estudadas (AM). Fonte: Pesquisa de campo 
Em termos de quantidade de carne consumida, há certa igualdade entre 2 a $3 \mathrm{~kg}$ e acima de $3 \mathrm{~kg}$ de carne. A cidade de Itacoatiara se destacou, acima de $3 \mathrm{~kg}$ (11 citações) e a cidade de Careiro mostrou o maior número (06 citações) para 1 a $2 \mathrm{~kg}$ para consumo. Em Manacapuru, todos os indivíduos entrevistados afirmaram que a quantidade de carne consumida nunca está abaixo de 1 a $2 \mathrm{~kg}$. Em todas as cidades houve indivíduos que não quiseram informar (NA) a quantidade comprada (Figura 4).

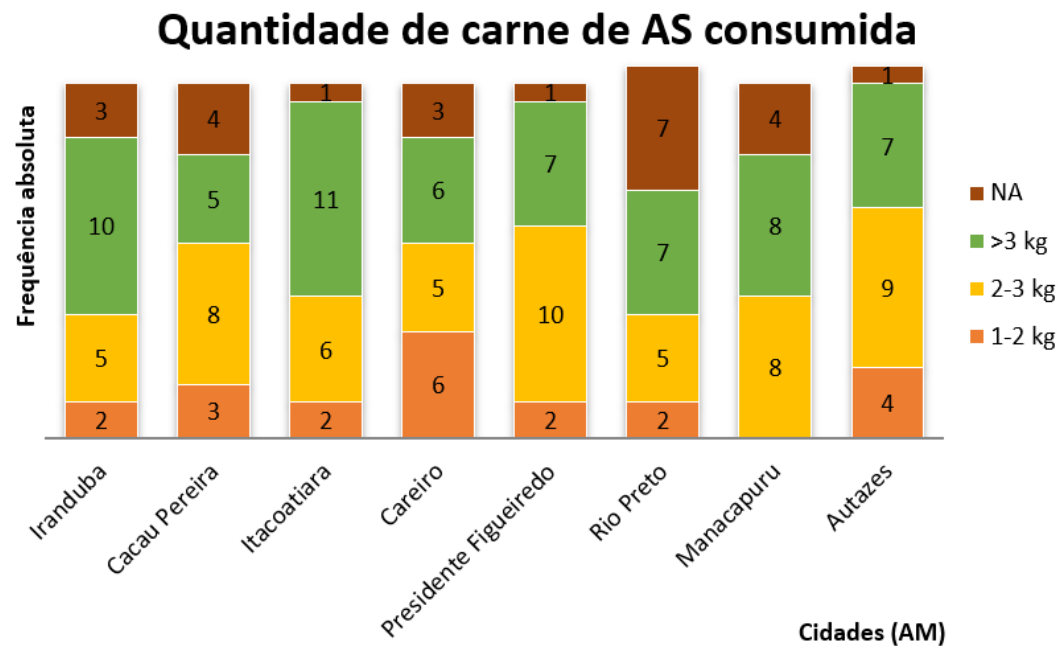

Figura 4: Frequência absoluta da quantidade de carne de AS nas cidades estudadas (AM). Fonte: Pesquisa de campo.

A compra da carne de AS nas feiras-livres nas cidades do estado do Amazonas é destinada à alimentação da família, principalmente em Itacoatiara (20 citações), como se pode observar no Figura 5. Apenas em Manacapuru foi relatado a compra de carne de AS para presentear um amigo (01 citação). Porém, com exceção de Itacoatiara, em todas as outras cidades, sempre houve quem não quisesse informar (NA) o destino da carne comprada na feira-livre.

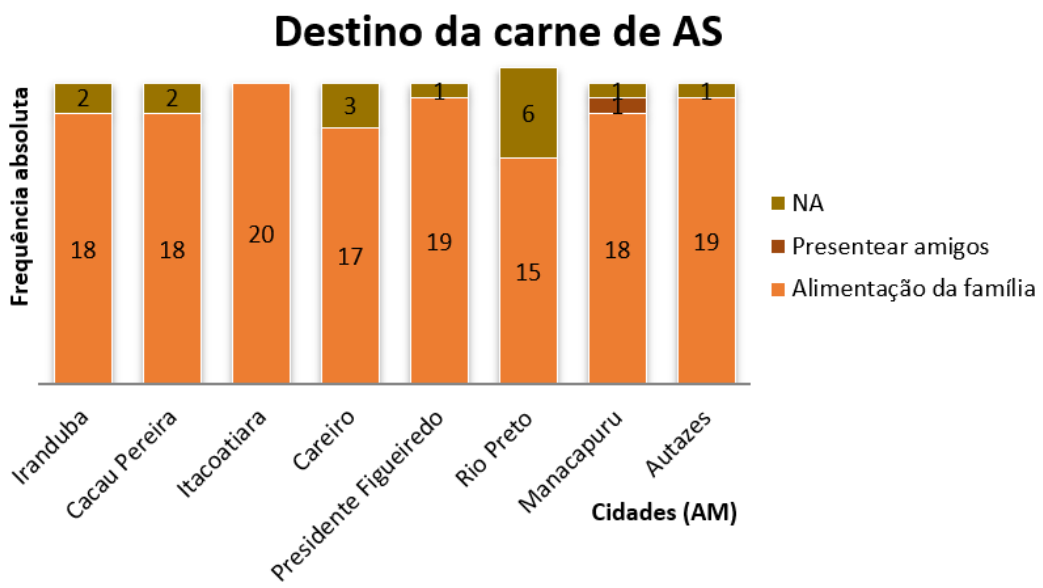

Figura 5: Frequência absoluta quanto ao destino da carne de AS nas cidades estudadas (AM). Fonte: Pesquisa de campo.

A principal razão da compra de carne de AS nas feiras-livres é o sabor diferente do animal. Isso ficou mais evidente na cidade de Itacoatiara (11 citações). Em apenas duas cidades, Iranduba e Autazes, o motivo da compra também é o preço (03 e 01 citações, respectivamente). Em todas as cidades a justificativa da compra da carne de AS é diversificar a dieta alimentar, principalmente em Autazes (09 citações). Em Iranduba, como se percebe no Figura 6, foi informado a compra de carne de AS por ser um hábito cultural da região (01 citação). 


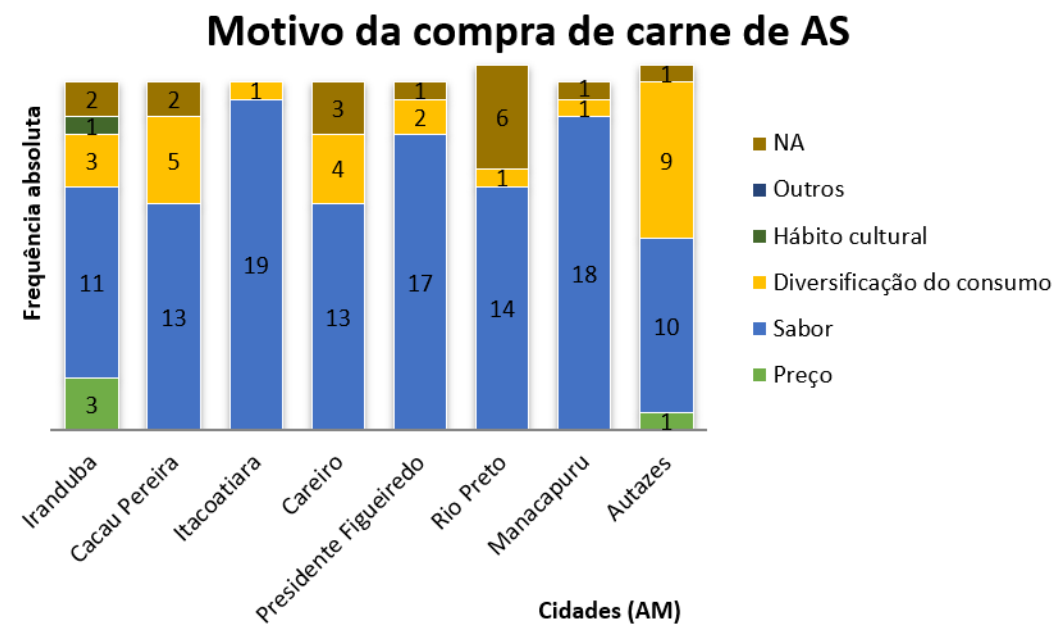

Figura 6: Frequência absoluta quanto ao motivo da compra de carne de AS nas cidades estudas (AM). Fonte: Pesquisa de campo.

Para os entrevistados, a procedência da carne de AS comercializadas nas feiras-livres é da natureza, ou seja, não procedem de criadouros, evidenciando um forte indício de caça nessa região. Na cidade de Itacoatiara, por exemplo, todos os entrevistados confirmaram isso (20 citações). Nas cidades de Iranduba e Cacau Pereira, desconhece-se a procedência da carne (03 e 01 citações, respectivamente). Com exceção de Itacoatiara, todas as outras cidades pesquisadas, alguns entrevistados não souberam ou não quiseram informar (NA) a procedência da carne de AS comercializada na localidade (Figura 7).

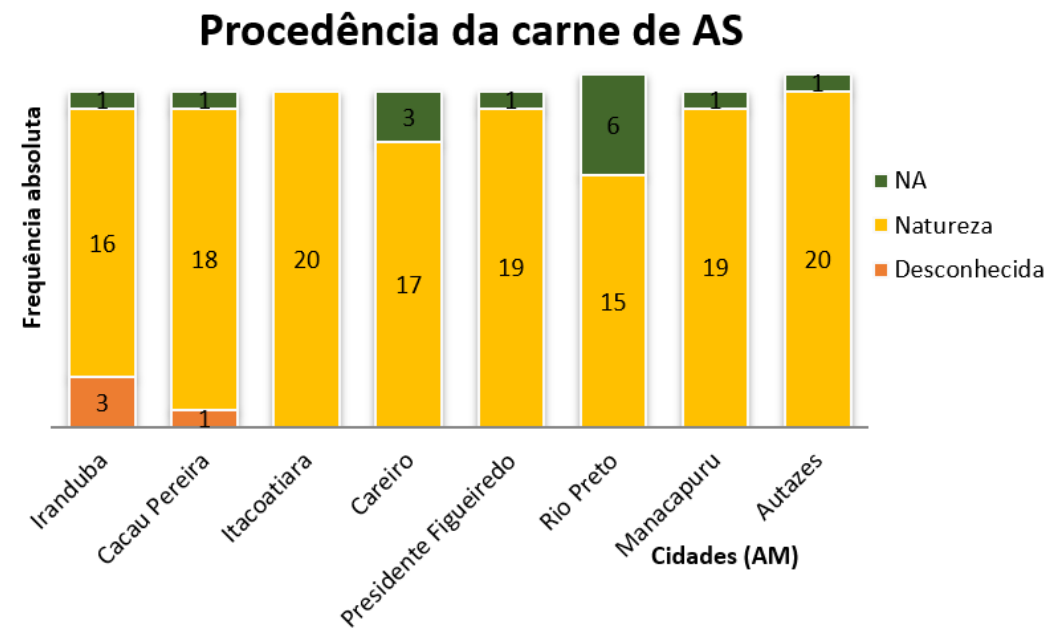

Figura 7: Frequência absoluta quanto ao motivo da compra de carne de AS nas cidades estudadas (AM). Fonte: Pesquisa de campo.

Aos entrevistados, quando se perguntou se já comprou algum AS para criação doméstica, houve certo equilíbrio nas respostas positiva e negativa. Isso é evidente na cidade de Itacoatiara (11 citações para não e 09 citações para sim). Em Presidente Figueiredo, o número de entrevistados que compraram AS para domesticar (11 citações) foi superior aos que não compraram (08 citações), diferenciando das cidades de Iranduba, Cacau Pereira, Careiro, Manacapuru e Autazes, em que a resposta negativa foi maior que a positiva (Figura 8).

Pelos resultados expostos é evidente que, nas feiras-livres das cidades estudadas na pesquisa, AS são vendidos ilegalmente. Esse comércio abastece tanto a dieta alimentar dessas cidades, quanto ao fator cultural de criar esses animais para domesticação. Infelizmente essa cultura ainda é muito evidente na Amazônia brasileira, uma vez que a população rural e ribeirinha tem fácil acesso à caça de AS para esse propósito. 


\section{Já comprou algum AS para criar?}

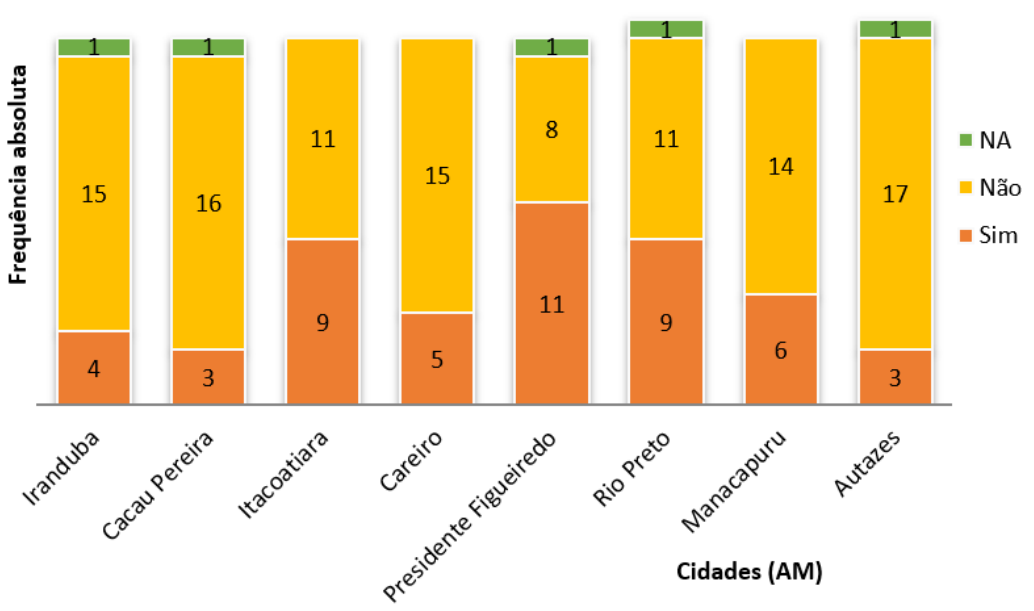

Figura 8: Frequência absoluta das respostas ao questionamento sobre a compra de AS nas cidades estudadas. Fonte: Pesquisa de campo.

\section{DISCUSSÃO}

Para as questões do comércio ilegal de AS, existe basicamente três atores: o caçador, o feirante (que pode ser considerado com atravessador) e o consumidor (17). Porém sua prática é mais complexa e pode envolver mais atores bem mais organizados. Porém, em se tratando da Amazônia, a rede de comercialização ilegal se caracteriza por envolver indivíduos de poder aquisitivo baixo. Isso foi evidenciado nas cidades onde o estudo foi realizado, pois apesar desses dados não constarem na pesquisa, foi evidenciado baixo nível econômico dos frequentadores das feiras livres, uma vez que a região norte do Brasil é considerada uma das regiões com o mais baixo Índice de Desenvolvimento Humano (IDH) do país, além do aspecto cultural que envolve o consumo de AS na região.

Em outras regiões do Brasil, sobre a temática aqui estudada, o quadro da pobreza social, a falta de alternativas econômicas e a precariedade na rede pública de ensino contribui para a atividade ilegal dos AS. Por outro lado, existe uma visão regional do ambiente amazônico, que requer necessariamente, a consideração dos interesses das comunidades locais, implicando o ambiente como sinônimo de subsistência destas populações (17). De fato, grande parte da dieta alimentar dessas cidades estudadas são retiradas diretamente da natureza, uma vez que a carne de AS vinda da floresta não carrega os impostos previsto pelo governo local.

Em relação à região norte do Brasil, mais especificamente o nordeste paraense, a população cabocla (Termo utilizado na Amazônia brasileira como uma categoria de classificação social...que em muitos casos é uma referência aos camponeses ou pequenos produtores rurais (18) tem como hábito cultural consumir proteína animal. Deste modo, no estado do Amazonas, por estar incluído na mesma, a situação não é diferente uma vez que ficou evidente que em todas as cidades visitadas, os frequentadores informaram que já compraram carne de AS para o consumo alimentar.

No que diz respeito à preferência, os vertebrados apresentam grande interesse para a caça de subsistência pelas populações humanas da Amazônia (17,19). Dentre os vertebrados, os ungulados como anta, veado (Mazama sp.), queixada (T. pecari) e caititu (T. tajacu) são os mais caçados, justificado pelo rendimento maior de carne para o consumo (20). Os animais considerados menores, como paca, cutia (Dasyprocata sp.), cutiara (Myoprocta sp.), quatipuru (Sciuris sp.) e tatus são menos caçados, por apresentarem baixo rendimento de carne (21).

Na pesquisa realizada, em grande parte os AS visualizados nas feiras livres vendidos, são os mesmos citados pelos autores. Porém, os registros fotográficos não foram possíveis de serem realizados. Sempre que houve a tentativa, os feirantes repreendiam os registros. Isso demonstrou que sabiam que estavam cometendo ilegalidade. A foto do exemplar da paca vendida na feira-livre de Manacapuru (AM), foi tirada depois de uma longa conversa com o responsável da venda. Onde foi acordado que não identificaríamos o local da feira e tão pouco o feirante que estava vendo o AS.

Conforme os dados para as cidades visitadas, mostrou-se que o estado do Amazonas necessita implementar políticas públicas para a temática. Essas vão desde a punição como também a educação ambiental. Mesmo diante dos dados 
concretos levantados nessa pesquisa, há os dados informais, como por exemplo na cidade de Novo Airão, que apesar de não haver feira livre, há depoimentos que indivíduos praticam a caça ilegal desses animais.

\section{Conclusão}

Desde a chegada dos portugueses no Brasil em 1500 a cobiça por AS se tornou uma prática cultural, que persiste até os dias de hoje. Nessa época os índios tinham como hábito a caça para alimentação, assim como mantinham AS em cativeiro, como se fossem animais doméstico. Dessa maneira, a mudar esse hábito ao longo dos anos é tarefa complexa para os governantes brasileiros, uma vez que existe enorme desigualdade social no país.

Quando se trata de adquirir AS, seja para consumo ou domesticação conclui-se que há também uma cadeia social envolvendo o comércio de AS nas cidades estudadas, resultando em fornecedores, intermediários e consumidores. Para isso deveria haver mais fiscalização por parte do IBAMA. Porém os investimentos político-econômicos são insuficientes e inadequados, além da falta de lugar adequado para os apreendidos, equipamentos, viaturas, contingente, treinamento e material para estudos, aprimoramento da legislação para a região, incentivos para a criação e investimento em criação são alguns fatores que, se bem administrados, colaborariam de fato para a temática.

Mesmo que disponibilizado, o investimento apenas em educação é insuficiente a pensar-se em uma perspectiva que envolva sustentabilidade. Ante uma realidade tão complexa, uma mobilização persistente de forças sociopolíticas e de recursos financeiros mais abrangentes são essenciais. Assim, a vontade política, a seriedade e a definição de metas a cumprir são irrelevantes. Essa concepção teria de ocorrer no âmbito das políticas de Estado e das definidas e postas pela sociedade, apesar das diferenças então existentes.

Nesses termos, a proteção aos AS poderá se concretizar, o que provavelmente, repercutirá nos contextos socioambientais nos quais tais animais têm estado presentes, embora vulneráveis à interesses geralmente ligados às ilegalidades diversificadas e sempre criativas. Mas isso só será possível se os investimentos forem disponibilizados quanto à informação, inteligência, prevenção de criminalidade e punição, e em relação à formação cidadã de autoridades, cientistas, técnicos e da população em geral, o que implicaria em educação em integral, criativa e continuada. Por certo, essas são perspectivas quase intransponíveis, notadamente, no contexto global contemporâneo e das áreas política e culturalmente periférica, a exemplo da Amazônia brasileira.

\section{Agradecimentos}

À Fundação Instituto para o Desenvolvimento da Amazônia (FIDESA).

\section{REFERÊNCIAS}

1. RESOLUÇÃO № 457, DE 25 DE JUNHO DE 2013. Ministério do Meio Ambiente: Brasil; 2013. [Acesso em: 19 set. 2018]. http://www2.mma.gov.br/port/conama/legiabre.cfm?codlegi=695

2. Lopes JCA. Operações de fiscalização da fauna: análise, procedimentos e resultados. In: ANIMAIS silvestres: vida à venda. 2. ed. Dupligráfica Renctas: Brasília, DF; 2003. http://www.renctas.org.br/wp-content/uploads/2014/06/ livro-vida-silvestre.pdf

3. Ministério do Meio Ambiente. 4ํ Relatório nacional para a Convenção sobre Diversidade Biológica. Série áreas protegidas do Brasil, n. 7, Secretaria de Biodiversidade e Florestas, Ministério do Meio Ambiente. Brasília, DF; 2010. https://www.mma.gov.br/estruturas/sbf2008 dcbio/ arquivos/quarto relatorio 147.pdf

4. Myers N. Tropical deforestation and mega extinction spasm. Sinauer Associates: Sunderland, Mass. (USA); 1986. https://www.ncbi.nlm.nih.gov/books/NBK219303/

5. Ministério do Meio Ambiente. Biodiversidade Brasileira. Ministério do Meio Ambiente: Brasil; 2018. http://www. mma.gov.br/biodiversidade/biodiversidade-brasileira 
6. Mittermeier RA, Gil PR, Mittermeier CG. Megadiversity: earth's biologically wealthiest nations. In: Animais silvestres: vida à venda. 2. ed. Brasília, DF: Dupligráfica; Renctas; 2003; http://www.renctas.org.br/wp-content/ uploads/2014/06/livro-vida-silvestre.pdf

7. Destro GFG, Pimentel, TL, Sabaini RM, Borges RC, Barreto R. Esforços para o combate ao tráfico de animais silvestres no Brasil. Ibama: Brasil; 2017. http://www.ibama.gov.br/sophia/cnia/periodico/ esforcosparaocombateaotraficodeanimais.pdf

8. Costa FJV, Ferreira JM, Monteiro KRG, Mayrink RR. Ciência contra o Tráfico: Avanços no Combate ao Comércio Ilegal de Animais Silvestres. João Pessoa: IMPRELL; 2017. https://www.researchgate.net/publication/327630299 Fortalecendo Parcerias a Favor da Biodiversidade Ciencia contra o trafico Avancos no Combate ao Comercio Ilegal de Animais Silvestres

9. Gaynor KM, Hojnowski CE, Carter NH, Brashares JS. The influence of human disturbance on wildlife nocturnality. Science. 2018; (360)1232-1235. https://doi:10.1126/science.aar7121

10. Jerozolimski A, Peres CA. Bringing home the biggest bacon: a cross-site analysis of the structure of hunter-kill profiles. Biological Conservation. 2003; 11(3):415-425. https://doi:10.1016/S0006-3207(02)00310-5

11. IBGE. Biomas. Instituto Brasileiro de Geografia e Estatística: Brasil; 2020. https://cnae.ibge.gov.br/en/component/ content/94-7a12/7a12-vamos-conhecer-o-brasil/nosso-territorio/1465-ecossistemas.html?Itemid=101

12. Mendes FLS. Apreensão de aves silvestres brasileiras que foram exportadas ilegalmente para Portugal. Revista Brasileira de Zoociências. 2018; 19(1):56-66. https://doi.org/10.34019/2596-3325.2018.v19.24688

13. Dias MBF, Cunha HFA, Dias TCAC. Caracterização das apreensões de fauna silvestre no estado do Amapá, Amazônia Oriental, Brasil. Biota Amazônia. 2014; 4(1):65-73. https://doi.10.18561/2179-5746/biotaamazonia.v4n1p65-73

14. Mendes FLS, Mendonca YSM. Perfil Socioeducacional dos Comerciantes Ilegais de Animais Silvestres em FeirasLivres da Amazônia. REMOA. 2017; 16(1):26-38. https://doi.org/10.5902/2236130829570

15. Silva EM, Oliveira ELR, Lima VFS, Borges JCG, Porto WJN. Aves silvestres comercializadas ilegalmente em feiras livres da cidade de Arapiraca, Alagoas. Enciclopédia Biosfera: Centro Científico Conhecer, Goiânia. 2015; 11(21):20452055. https://www.conhecer.org.br/enciclop/2015b/biologicas/aves\%20silvestres.pdf

16. Renctas. Investigar o tráfico ilegal de animais e plantas silvestres da fauna e da flora brasileiras. Rede Nacional de Combate ao Tráfico de Animais Silvestres: Brasil; 2014. http://www.renctas.org.br/wp-content/uploads/2014/11/ Rel Fin CPI Trafico 1.pdf

17. Mendes FLS. Ilegalidades no comércio de animais silvestres nos estados do Pará e do Amazonas. [Tese Ph.D.]. Universidade Federal do Pará, Núcleo de Altos Estudos Amazônicos, Programa de Pós-Graduação em Desenvolvimento Sustentável do Trópico Úmido: Belém. Brasil; 2010. http://www.ppgdstu.propesp.ufpa.br/ARQUIVOS/teses/ TESES/2010/Fabricio\%20Lemos\%20de\%20Siqueira\%20Mendes.pdf

18. Lima DM. A Construção histórica do termo caboclo: sobre estruturas e representações sociais no meio rural amazônico. Novos Cadernos NAEA. 1999; 2(2):1-28. http://dx.doi.org/10.5801/ncn.v2i2.107

19. Souza GM, Soares-Filho AO. O Comércio ilegal de aves silvestres na região do paraguaçu e sudoeste da bahia. Enciclopédia Biosfera. 2005; 1(1). http://www.conhecer.org.br/enciclop/2005.htm

20. Peres CA. Synergistic Effects of Subsistence Hunting and Habitat Fragmentation on Amazonian Forest Vertebrates. Conservation Biology. 2001; 15(6):1490-1505. https://doi.org/10.1046/j.1523-1739.2001.01089.x

21. Almeida MB, Lima EC, Aquino TV, Iglesias MP. Caçar. In: Cunha MC, Almeida MB. (Org.) Enciclopédia da floresta - o Alto Juruá: prática e conhecimentos das populações. São Paulo: Companhia das Letras; 2002. https://searchworks. stanford.edu/view/4809098 